\title{
Barriers and facilitators to pharmacotherapy for alcohol use disorders in primary care: results of a qualitative study in 4 va primary care clinics
}

\author{
Emily Williams ${ }^{1,2^{*}}$, CE Achtmeyer ${ }^{1,5}$, JP Young ${ }^{1}$, KA Bradley ${ }^{2,3,4}$, D Berger ${ }^{5}$, MB Siegel $^{6}$, G Curran$^{7}$, EJ Ludman ${ }^{4}$,
} GT Lapham ${ }^{4}$, AHS Harris ${ }^{8}$, M Forehand ${ }^{9}$

From INEBRIA 12th Congress,

Atlanda, GA, USA. 24-25 September 2015

\section{Background}

In the context of routine population-based alcohol screening to identify primary care (PC) patients who might benefit from brief intervention, many patients identified will have alcohol use disorders (AUD) [1] and will likely require more intensive treatments. FDA approved medications are recommended to treat AUD $[2]^{\mathrm{b}}$ and could be offered in PC. Currently, use of AUD medications is extremely rare. [3] This qualitative study sought to understand barriers and facilitators to prescribing AUD medications in PC.

\section{Material and methods}

Key contacts and snowball sampling were used to recruit 23 PC providers (MDs and NPs) from 4 Veterans Health Administration (VA) clinics. Providers completed semi-structured interviews in person, which were recorded, transcribed, and analyzed using rapid teambased qualitative methods.

\section{Results}

Few participating providers had prescribed AUD medications. Providers consistently reported concern regarding lack of time to adequately address AUD, need for training in prescribing AUD medications, and need for ongoing support from mental health or on-site staff to provide behavioral counseling. However, some participating providers were more willing than others to consider prescribing AUD medications. Providers who were

\footnotetext{
* Correspondence: Emily.Williams3@va.gov

${ }^{1}$ Center of Innovation for Veteran-Centered Value-Driven Care, Health Services Research \& Development, Veterans Affairs Puget Sound Health Care System, Seattle, USA

Full list of author information is available at the end of the article
}

more willing viewed prescribing for AUD as part of their role as a PC provider, framed medications as a potentially effective "tool" or "foot in the door" for treating AUD, and believed that providing AUD medications in PC may catalyze change while reducing stigma and other barriers to specialty addictions treatment. Those who were less willing believed that substantial programmatic changes would be needed to facilitate provision of AUD medications in PC, had less belief in the ability of "pills" to treat AUD, and believed AUD treatment was best left to specialty settings.

\section{Conclusions}

With training and additional behavioral staff, it may be possible to capitalize on some providers' willingness and optimism to increase provision of medications as part of PC for patients with AUD.

\begin{abstract}
Acknowledgements
The authors gratefully acknowledge the participants of this study for allowing us to solicit and report on their perspectives. We also thank the clinical and administrative coordinators at each of the clinics for facilitating our visits. This study was funded by VA Health Services Research \& Development and VA Quality Enhancement Research Initiative (RRP 12-528; Williams PI). Dr. Williams is supported by a Career Development Award from VA Health Services Research \& Development (CDA 12-276). Dr. Bradley's time on this study was supported by the Center of Excellence for Substance Abuse Treatment and Education (CESATE) at VA Puget Sound.

\section{Authors' details}

${ }^{1}$ Center of Innovation for Veteran-Centered Value-Driven Care, Health Services Research \& Development, Veterans Affairs Puget Sound Health Care System, Seattle, USA. ${ }^{2}$ Department of Health Services, School of Public Health, University of Washington, Seattle, USA. ${ }^{3}$ Group Health Research Instistute, Seattle, USA. ${ }^{4}$ Department of Medicine, School of Medicine, University of Washington, Seattle, USA. ${ }^{5}$ Primary and Specialty Care Medicine, Veterans Affiars Puget Sound Health Care System, Seattle, USA. ${ }^{6}$ Department of Social and Behavioral Sciences, School of Public Health, Boston University,
\end{abstract}


Boston, USA. 'Division of Health Services Research, Department of Psychiatry, University of Arkansas for Medical Sciences, Arkansas, USA. ${ }^{8}$ Palo Alto Health Care System, Veterans Health Administration, Palo Alto, USA. ${ }^{9}$ Foster School of Business, University of Washington, Seattle, USA.

Published: 24 September 2015

\section{References}

1. Williams EC, Rubinsky AD, Lapham GT, Hawkins EJ, Chavez LJ,

Rittmueller SE, Hawkins EJ, Grossbard J, Kivlahan DR, Bradley KA: Prevalence of Recognized Alcohol and Other Substance Use Disorders among VA Outpatients with Unhealthy Alcohol Use Identified by Routine Alcohol Screening. Drug and Alcohol Dependence 2014, 135:95-103.

2. NIAAA: Helping Patients Who Drink Too Much: A Clinician's Guide (Updated 2005 Edition) Washington, D.C.: NIH, US DHHS; 2007.

3. Harris AH, Kivlahan DR, Bowe T, et al: Pharmacotherapy of alcohol use disorders in the Veterans Health Administration. Psychiatr Serv 2010, 61:392-8.

doi:10.1186/1940-0640-10-S2-P12

Cite this article as: Williams et al:: Barriers and facilitators to

pharmacotherapy for alcohol use disorders in primary care: results of a qualitative study in 4 va primary care clinics. Addiction Science \& Clinical Practice 2015 10(Suppl 2):P12.

\section{Submit your next manuscript to BioMed Central and take full advantage of:}

- Convenient online submission

- Thorough peer review

- No space constraints or color figure charges

- Immediate publication on acceptance

- Inclusion in PubMed, CAS, Scopus and Google Scholar

- Research which is freely available for redistribution

Submit your manuscript at www.biomedcentral.com/submit 